\title{
Do Future Mobility Concepts Fit Consumer Demand?
}

\author{
An Organizational Perspective. \\ [Laura Lang \& Alwine Mohnen]
}

\begin{abstract}
Electric vehicles, features for autonomous driving, and car-sharing services in combination with mega trends - such as urbanization and digitalization - have the potential to revolutionize the entire mobility sector. Our study addresses the ongoing shift in values and the kind of individual consumer demand that has to be met by providing innovative and flexible concepts for future transport. In particular, we call into question what challenges need to be faced, when various new technologies and business models are integrated. Our qualitative approach is based on the use of semi-structured interviews with representatives from a traditional car manufacturer. By investigating the expectations and actions of different stakeholders from an organizational perspective we find important predictions concerning the inevitable changes in consumer behavior and consequently in organizational strategy. It becomes clear that one of the key challenges is an appropriate steering system to motivate innovation activities and enhance creativity in order to ensure long-term success in an increasingly competitive market environment.
\end{abstract}

Keywords - innovation, electric vehicles, autonomous driving, car-sharing, steering system.

\section{Introduction}

The automotive industry is undergoing a revolutionary transformation resulting in a shift from private car ownership as a guarantor of individual mobility to a more flexible approach. "The use of digital technologies in order to economize the mobility sector, making it more efficient and intermodal, cannot be stopped. The automobile with its combustion engine was only the first generation appliance" (Canzler and Knie, 2016, p. 56). Technological advances and changing mobility requirements of customers paired with so-called mega trends like digitization and urbanization create windows of opportunities for novelties with innovative business models and, at the same time, pose unprecedented challenges for traditional car manufacturers. Concentrating on innovative technologies like electric vehicles or autonomous driving and the expansion of the service sector (e.g. car sharing) might be a promising path to follow for existing firms. However, to remain competitive in the future and to meet the novel demands of a more global society, existing organizations need to act rapidly and to be innovative at lowest possible costs (Wilson and Doz, 2011).

In that context, Ederer and Manso (2013) suggest that even though traditional, performance-based management or steering systems enhance productivity in an organization, they might also inhibit creativity, which is indispensable in times of rapid and revolutionary change. Experimentation

\section{Laura Lang}

Prof. Dr. Alwine Mohnen

TUM School of Management - Technische Universität München Germany with resources may lead to innovations and will ultimately help to remain competitive in the long term. Hence, different and appropriately designed incentive schemes, as well as more tolerance for failure are necessary (Manso, 2011).

Technical advances, a shift in values, and new regulations with their influence on organizations and industries is what makes the current transition interesting to explore. To address this newly emerging field of research, we present a qualitative approach (semi-structured interviews) to provide descriptions and implications on how to deal with changes in consumers' individual mobility behavior from an organizational perspective. In particular, we aim to A) describe the current developments in the automotive industry with regard to newly emerging technologies; B) provide an understanding of strategic orientation and organizational aims; and C) present implications on how to meet changing customer demand. Our study contributes to the existing literature by pointing out current challenges for traditional car manufacturers within and outside the organization suggesting that it has never been more important to further promote the courage to take new paths. Providing innovative mobility options and thereby addressing the shift in values is indispensable to ultimately ensure long-term success in an increasingly competitive market environment.

The paper is organized as follows: The first section provides an overview of the literature and theoretical framework. The methodology is described in the second section. In the third and fourth section, the results of the interviews are presented and discussed. Conclusions are drawn and recommendations for future research are given in the final section.

\section{Theoretical Framework}

\section{A. Managing Transitions}

A transition within an industry or organization is an ongoing process of interaction between numerous stakeholders with differing expectations, perceptions and intentions to achieve certain goals (Geels, 2005; Geels and Schot, 2007). As current developments in the automotive industry demonstrate, the inescapable necessity for reorientation and adaption can be forced in various ways, for example, by innovative products from new competitors, changing environmental conditions or new legal requirements (Truelove and Kellogg, 2016).

Bloom, Genakos, Sadun, and Van Reenen (2012) defined a well-managed organization as "continuously monitoring and trying to improve its processes, setting comprehensive and stretching targets, and promoting highperforming employees" (p.6). Even though it remains unclear as to which extent management practices ultimately 
Proc. of The Eighth Intl. Conf. On Advances In Economics, Social Science and Human Behaviour Study - ESSHBS 2018

Copyright (C) Institute of Research Engineers and Doctors, USA. All rights reserved.

ISBN: 978-1-63248-156-6 doi: 10.15224/978-1-63248-156-6-22

promote or hinder stability and economic growth, a number of studies propose that existing firms with more traditional structures may struggle when faced with technological change or shifting markets (Christensen and Bower, 1996; Gioia and Chittipeddi, 1991; Kaplan and Orlikowski, 2013; MacKay and Chia, 2013; O'Reilly 3rd and Tushman, 2004; Schilling, 1998; Tripsas and Gavetti, 2000; Truelove and Kellogg, 2016)

Manso (2011) and later Ederer and Manso (2013) investigated the impact of incentive schemes on a firm's management of innovation projects using an experimental approach. The authors conclude that other than classic payfor-performance schemes, a diverse combination of reward for long-term success and tolerance for failure encourage creativity and ultimately promote innovation activities. It is furthermore shown that private ownership structures are better suited to incentivize innovation than public ownership structures (Ferreira, Manso and Silva, 2012). Christensen and Bower (1996) investigated why leading, financially strong and customer-oriented organizations with all necessary skills and resources fail to stay competitive even though they have invested heavily in new technologies. Research in this field comes to the conclusion that these firms are too careful and fail when the innovation does not meet prominent customer needs, addresses a new market or requires a change in strategy (Brown and Eisenhardt, 1995, 1997; Castellion and Markham, 2013; Ernst, 2002; Garcia and Calantone, 2002).

Borup, Brown, Konrad and Van Lente (2006) bring together different economic studies in the context of changing market behavior, innovation and technology diffusion showing "[...] that expectations of rapid technological progress, for instance, may reduce consumers' willingness to adopt new technologies in the expectation of successor technologies yet to come" (p. 288). With regard to the automotive sector, research on the organizational, as well as on the customer side has so far been limited to only single elements of future mobility concepts such as electric vehicles (Bakker, Maat and van Wee, 2014; Fazel, 2014), autonomous technologies (Bertoncello and Wee, 2015; Bimbraw, 2015; Campbell, Egerstedt, How, and Murray, 2010) or mobility services (Canzler and Knie, 2016; Fagnant and Kockelman, 2014; Spieser, Treleaven, Zhang, Frazzoli, Morton and Pavone, 2014). In light of the fact that they may all be related, this paper aims to call into question what particular challenges need to be faced when various new concepts are integrated in order to remain competitive and meet changing consumer demand.

\section{B. Future Mobility Concepts}

Due to ongoing pressure by regulators to reduce emissions, manufacturers are forced to invest in alternative powertrain technologies and extend their product portfolio with hybrid- or full-electric vehicles (Bakker, Maat and van Wee, 2014; Council of the European Union, 2017). However, limited range and higher prices compared to classical vehicles with combustion engines are the main obstacle for widespread customer acceptance (Fazel, 2014). Besides the fact that it takes considerably longer to charge the battery than to refuel a combustion engine, Bakker, Maat and van Wee (2014) point out the following additional difficulties: insufficient public recharging infrastructure, uncertainties related to the charging behavior, and a lack of technical standards for charging equipment. In light of the mentioned drawbacks, the industry and policy makers need to further develop, support, and invest in electric vehicles to extend the range, reduce charging time and to develop the infrastructure in order to provide an attractive alternative for the customer (Knupfer, S., Hensley, R., Hertzke, P., Schaufuss, P., Laverty, N., 2017). It can be assumed that within the next years, electric mobility will have become an inherent part of a sustainable mobility sector and people's everyday life in urban societies, not only due to climate change and stricter regulations in cities, but also due to further technological advancements and widespread awareness.

On-demand mobility usually refers to car-sharing operators offering a flexible network of vehicles in urban areas for a spontaneous, short-term rental or small, one-way journeys. A digital platform captures and visualizes the information about the position, availability and cost of different cars. Typically customers pay a one-time registration fee and an additional amount of money each time they rent a vehicle having quick and convenient access via their smartphones (Canzler and Knie, 2016; Truelove and Kellogg, 2016). By allowing for short-term limited use of asset car sharing represents an attractive alternative to traditional vehicle ownership and seems to replace the paradigm of private property for certain target groups (Canzler and Knie, 2016). This new mobility service might indicate an unavoidable shift in the perception or decisionmaking of future customers and is likely to become an even more important component in the mobility sector within the next few years. In combination with autonomous driving technologies, more efficient systems can be realized ultimately making the driver obsolete (Fagnant and Kockelman, 2014).

Autonomous vehicles take into account sensory information from their local environment and navigate paths without human interaction, obeying traffic regulations while at the same time exchanging information with other vehicles on the road (Campbell et al., 2010). They operate with less chance of error and at higher speeds due to an increased system reliability and faster reaction time compared to human abilities. Thereby traffic accidents will be significantly reduced while roadway capacity is increased, leading to a better traffic flow (Bimbraw, 2015; Fagnant and Kockelman, 2014). Since commuting times e.g. with public transport are preferably spent online using a smartphone, autonomous driving in combination with digital media enables the passenger to use time in a more productive and satisfactory way (Canzler and Knie, 2016). Autonomous technologies offer a number of previously mentioned advantages. Nevertheless, there are still challenges for policy makers to implement a suitable legal framework (Bonnefon, Shariff and Rahwan, 2016). Customers are struggling with ethical issues and lack in imagination or acceptance for this new technology. However, the sector is expanding more and more and it is assumed that both traditional and new automobile manufacturers will launch their first autonomous features by 2020, enabling safe and comfortable travelling, providing a relief from various unpleasant driving situations (Bimbraw, 2015). For the reasons stated above, this innovative technology might fundamentally change the predominant understanding of the automobile (Bertoncello and Wee, 2015). 
Proc. of The Eighth Intl. Conf. On Advances In Economics, Social Science and Human Behaviour Study - ESSHBS 2018

\section{Method}

In order to identify key aspects of the transition in the automotive industry, a qualitative research design was applied, conducting semi-structured interviews with experts from a traditional car manufacturer. This inductive method was chosen because it is the most practical way to investigate from within and obtain information about different themes in limited time, guaranteeing openness for differing views and perceptions (Langley, 1999). The initial sample consisted of 18 expert interviews with strategists, marketers and engineers from a single organization on different levels of high and middle management. Interviews were conducted on the basis of a uniform guideline and carried out informally, individually and in native language to promote openness and allow experts to talk freely and at their desired level of detail (Gläser and Laudel, 2010). At the same time, the standardized form of the interview ensures all the relevant information is retrieved, can be compared to existing literature findings and facilitates consistent structuring for further analyses (Helfferich, 2011).

To develop conceptual insights, interview transcription and respective data analysis were performed using MAXQDA 12. Content categories and theoretical constructs were formalized in order to summarize analytical observations, generate a systematic set of explanations and ultimately a proposal of theory (Charmaz, 2006; Glaser and Strauss, 1967). Following a triangulation approach suggested by Eisenhardt (1989) an initial coding system was developed to generate a powerful research perspective while inductive coding as a process of continuing analysis ensured the necessary flexibility (Mayring, 2010; Miles, Huberman and Saldana, 2014). For reasons of internal validation and intercoder reliability, the developed coding system and conclusions drawn through analysis were checked with several independent researchers to ensure the concepts are applicable and interpretations comprehensible (Campbell, Quincy, Osserman and Pedersen, 2013).

\section{Results}

While analyzing the interview transcripts, three focus areas were identified: A) future mobility, B) organizational change and C) customer's mobility behavior. An overview of respondents' statements, evaluations and individual perceptions is provided for the respective categories.

\section{A. Future Mobility}

Participants agree that even though environmental awareness is increasing and the conversion from a combustion engine to an electric vehicle does not cause significant behavioral changes, the customer is still satisfied with the status quo. As stated by several participants, there is still one crucial disadvantage: "a range that meets the customers' expectations" (S). Nevertheless, the regulator is exerting increasing influence by imposing restrictions on the industry and creating incentives for electric vehicles. In addition, new players and increased competition induce progress by creating pressure on existing firms and shaping customer needs. According to the experts, electric vehicles will continue to grow in importance. Hence, more favorable solutions in all kinds of vehicles including emotional concepts such as sports cars and convertibles are necessary to meet future market demand.

Respondents are furthermore in agreement that carsharing services are becoming an indispensable element of future transport. A variety of platforms and services are delivered irrespective of whether a private vehicle is owned or not. Mobility services offer possibilities to generate a new profitable business and capture new market segments, as well as to enlarge the customer base: "People pay for a test drive. Just perfect" (Q). Hence, new customers can be attracted by providing a valuable addition to the traditional product portfolio. Further advantages include that, on the one hand, mobility-on-demand helps to ease the situation of increasing urbanization from a cost side, as well as for reasons of space. On the other hand, it is a good opportunity to generate initial contact with electric mobility and thereby increase the acceptance of new technologies: "The customers are impressed and cities are satisfied" $(N)$.

With regard to autonomous driving, respondents fully agree that automation plays a significant role in the future. According to their expertise, it is the fastest growing technology within the automotive sector. Increased competition is leading to significant improvements with effective alliances as one of the key stimulants to establishing innovative concepts. However, reaching full automation is still seen to be far off due to the associated costs and the necessary clarity of standards set by legislation. In addition, respondents state that customers are struggling to assess the range of changes and its positive consequences. They fear restrictions regarding autonomy and self-determination as well as safety and ethical issues. Nevertheless, experts are convinced that "people will love it" $(P)$ and it will be the solution to all urban problems: worries of parking, stop-and-go traffic and traffic jams.

Another salient topic was digitization becoming increasingly important. Participants agree that a new kind of speed and agility is required in order to continue to fulfill more sophisticated customer demands. New business models are competing with earlier ones resulting in different approaches to maintain and even enhance market share within and beyond the bounds of the industry. The organization is forced to invest in comprehensible digital services and its smart integration into a new generation of vehicles: "The customer wants to be fully connected - 24 hours, 7 days a week - and rightfully expects the same from our cars" (L). As can be observed in the consumer electronic industry with its short development cycles, a greater connectivity may ultimately lead to the car being just another device in the so-called internet of things.

\section{B. Organization}

A general assessment of the strategic alignment and orientation is presented by differing opinions and attitudes towards change within the organization.

By integrating different mobility concepts and thereby offering the customer an even better product or service the organization can benefit from new business models. The majority of respondents are contemplating the transition with optimism and have confidence in the company and its strategic direction: „I don't have any fear. Our engineers are among the best in the world and have it all covered. The intelligence and passion of the people who work here lead to 
Proc. of The Eighth Intl. Conf. On Advances In Economics, Social Science and Human Behaviour Study - ESSHBS 2018

Copyright (C) Institute of Research Engineers and Doctors, USA. All rights reserved.

ISBN: 978-1-63248-156-6 doi: 10.15224/978-1-63248-156-6-22

the best possible results" $(Q)$. However, differing views and a certain variability of attitudes towards change within the organization can be observed. The transition is also seen as a very challenging phase which will require compromises. People have to be willing to get involved or even reinvent themselves: "The potential is all there. I would like to see more courage and willingness to make decisions within and outside the organization" (A). A negative attitude towards change and a growing discomfort with regard to the future of the organization can also be observed by respondents stating that strategic decisions are taken too slowly and running in too many directions. They claim that competitors and especially new players on the market are strategically better positioned and address current challenges with more proactive measures: "We are facing a strategic dilemma. We have to engage in a business that appears to be less attractive than our original business model" $(N)$.

Interview responses collectively describe the current transformation as being the greatest change within and outside the automotive industry so far. Experts emphasize the necessity for strategic change, the importance of new partnerships and the enormous impact of global and social mega trends. Respondents sense a general uncertainty and demand more openness for innovation and creativity. The transition is assessed to require an open-minded approach and a shift in corporate values. When the subjects were asked about the challenges and potentials of traditional car manufacturing companies, the majority commented that the established know-how and core competencies are a prerequisite for delivering a good and high-quality product. However, traditional processes and structures might also be an obstacle to developing and engaging in new business models. Experts indicate that taking a parallel path between traditional vehicle technologies and innovative mobility solutions currently is the best approach to satisfy customer needs and to achieve both high volumes and profitability.

Further analysis revealed another aspect with regard to the management system and is very important being mentioned. Respondents see great potential in developing the inflexible steering system and criticize the dominance of financial figures. Without having directly asked about the topic, the code profitability / investment / return / controlling (steering / management system) is added subsequently. Measuring proximity and overlap (Fig. 1), the respective code has the highest correlation with the code criticism / conflict / improvements supporting the importance the identified topic.

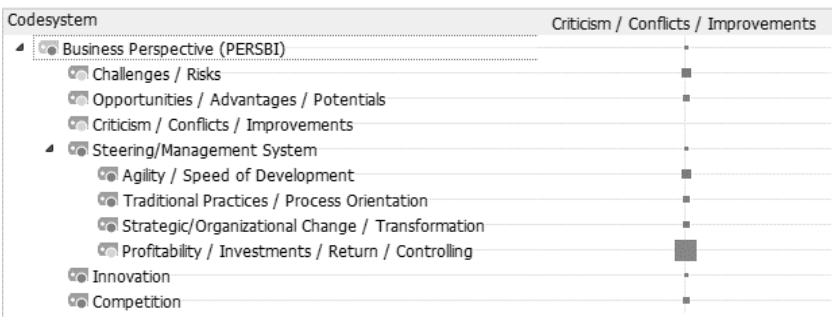

Figure 1. Code Relation Matrix.

Experts state that currently applied incentive schemes and lack of tolerance for failure are opposed to innovation activities: "An engineer or project leader usually has responsibility for costs and is measured on the basis of an outdated system. That corset prevents creative proposals and the integration of new customer functions" (D). Since innovations in their first generation usually lack in high profitability, the steering logic needs to be broadened because ultimately, when "financial figures are prioritized at the cost of product substance, the organization is risking a promising alignment of the portfolio" $(R)$.

\section{Customers}

The customer perspective is captured by asking participants about behavioral changes and individual needs for mobility. Changes in customer behavior are characterized by new value structures, an increasing environmental awareness and shifts towards a digital world of experiences: "social change in connection with new technologies and digitization thus leads to other expectations of the vehicles" (B) and better use of time: "The need to do something different or for new experiences is there. That can range from sleeping to working" (I). The majority of respondents reported that a simple integration of devices, high connectivity and personalization are playing an increasingly important role: "The customers require services that are supposed to make life easier" (L). In addition, comfort and privacy are key drivers for acceptance. Analyzing the statements of the respondents, furthermore shows that mobility behavior changes also as a function of age: "the new generation has a very different understanding of mobility" $(O)$. Moreover, depending on the generation, change is observed to take place less rapidly in the older age groups and much faster than expected in the younger ones.

Participants indicate that personal and individual mobility is a basic need relating to autonomy, freedom and self-determination: "Mobility is deeply rooted in the need structure of a human being" (H). Even though, basic mobility needs will remain stable in the future they are supplemented by an additional mobility demand due to an increasing number of all-encompassing, wide-range and usecase-specific offerings. As a consequence of the shift in values, the car loses its significance as a status symbol: "it is not that important to own something as long as it can be used" $(N)$. Declining relevance of possession is observed and mobility services on demand are offered whenever or wherever a car is needed. Car-sharing services might be the adaptable alternative to one's own car, but, at the same time, customers are somewhat limited due to vesting restrictions and only temporary usage: "One's own, individual car will continue to exist. That is what customers' claim. However, attitudes toward mobility are changing and evolving towards more use-case-specific requirements" $(O)$.

It is furthermore anticipated that there will still be a desire for premium solutions as well as different levels of quality and performance. That is supported by several experts stating that in the far future the privately owned car will only be a niche or premium product for those who are still willing to pay for luxury, design and emotionality. Looking at the aviation business - an example illustrated by one expert - customers have always asked and always will ask for expensive and luxury transportation, on the one hand, and simple or inexpensive alternatives to get around on the other: "Forms of individual transportation are still desired. A premium segment exists. In the future there might be the car for the common people and a premium variant with scented leather" (I). 
Proc. of The Eighth Intl. Conf. On Advances In Economics, Social Science and Human Behaviour Study - ESSHBS 2018

Copyright (C) Institute of Research Engineers and Doctors, USA. All rights reserved.

ISBN: 978-1-63248-156-6 doi: 10.15224/978-1-63248-156-6-22

\section{v. Discussion}

After profound analyses, the challenges caused by the current transition in the automotive industry are multifaceted, and various influencing factors need to be taken into account. Results illustrate that not only the shift in values is shaping new forms of mobility and ultimately the future of a whole industry. Different business models from the old and new world exist in parallel and are even competing, while core competencies are becoming superfluous through new technological breakthroughs. The automotive market needs to expand the provision of new solutions for alternative drivetrains and, even further, the offering of mobility solutions that seamlessly merge with the digital world of experiences. The combination of different mobility concepts can address customer requirements in a more comprehensive manner.

Findings suggest that new and innovative modes of transport may guarantee for the satisfaction of mobility desires and increase the capacity and efficiency of transport modes without the direct need for private car ownership. Integrating shared vehicles and autonomous driving functions may be the ultimate and financial profitable solution to counteract increasing problems of urban transport. According to results, which are in line with Burns, Jordan and Scarborough (2013), as well as Fagnant and Kockelman (2014), a shared, driverless fleet could furthermore provide better mobility experiences and services at radically lower costs. However, findings highlight that the private car still has its justification due to individual preferences and a certain desire for self-determination and differentiation. As results share similarities with Canzler and Knie (2016), new business models seem to be struggling within the traditional transportation frameworks.

Evidence was found that the political regime is one of the most powerful elements influencing the actions and interest of the other stakeholder groups, underlining an economic path dependence (Geels, 2005). Through restrictions, on the one hand and incentives on the other, the regulator is giving direction to the system while both industry and customers are not completely free in their decision-making or preferences. Nevertheless, results also illustrate that incentivizing is crucial and helps to stabilize emerging technologies such as electric mobility in an early phase, bearing in mind the positive impact on climate and urban conflicts.

In addition to provisioning vehicles as the necessary hardware and their operation through established car manufacturing companies, focusing on a digital facet of future transportation should not be underestimated. The study's results provide evidence that digital platforms are increasingly gaining in importance, offering a higher level of connectivity and a new experience while driving. Digital players are welcomed by customers providing a more modern and innovative approach but also striking fear in traditional organizations that they will conquer the automotive market with the right answers and respective resources for a fast-moving society.

However, experts see a certain chance in increased competition driving the industry forward. Bloom et al. (2012) confirm that management practices are observed to be better in more competitive environments, coming to the conclusion that power struggles, on the one hand and the creation of coalitions on the other, improves efficiency and leads to more comprehensive solutions in a shifting market.

Moreover and especially in times of change, managers and employees might fear losing their jobs and therefore act more self-interested to achieve their individual goals. Empirical evidence from Manso (2011) and Christensen and Bower (1996) state that more tolerance for failure and alternative incentive schemes for long-term reward are necessary in order to be more creative and explore new approaches instead of repeating what has been done in the past (Ederer and Manso, 2013). This study's findings confirm that traditional practices and inflexible processes can be an obstacle for developments outside the typical field of activities and processes. Ultimately, discovering new strategies and engaging in innovation activities are indispensable to remaining competitive in the future and to addressing the customers' needs.

Ultimately, the success or failure of new mobility concepts largely depends on powerful actors supporting the idea of the innovation. This underlines just how important it is to meet critical customer demands such as flexibility, ease of use, convenience, comfort and privacy, as further analysis revealed. As results furthermore demonstrate, new products and services are only successful when price and performance improvements lead to widespread acceptance. Standards and formal rules need to be created in alignment with customers adapting their preferences and mobility practices accordingly: "the alignment between these elements leads to a new technological 'momentum'"(Geels, 2005, p. 447).

\section{vI. Conclusion}

The findings highlight that it has never been more important to make smart strategic decisions to exploit the full potential in the future of mobility. Any change involves a specific risk but also offers opportunities. Whether the transition in the automotive industry will be successful for traditional manufacturers depends on how emerging technological opportunities are transferred into a desired customer benefit. Digital services and innovative products with a high level of quality are essential to remaining successful in an increasingly complex market environment. From a corporate and organizational point of view, the results show a strong need for redesigning incentive systems and performance measurement. An inflexible management system and traditional process are hindering established organizations from developing products and services with the necessary creativity, speed and agility. Perspectives need to be broadened, especially for innovation projects and business models outside the traditional scope of the organization in order to compete with new and heavily investing players on the market.

Existing literature and different studies present various approaches to investigating the issue of firms might lose their position of industry leadership. This study tries to be one step ahead and contributes to an understanding of how to take advantage of the great opportunity to proactively shape the future of mobility, always bearing in mind the importance of customer preferences. 
Proc. of The Eighth Intl. Conf. On Advances In Economics, Social Science and Human Behaviour Study - ESSHBS 2018

Copyright (C) Institute of Research Engineers and Doctors, USA. All rights reserved.

ISBN: 978-1-63248-156-6 doi: 10.15224/978-1-63248-156-6-22

\section{A. Limitations}

Although the approach to choose an inductive methodology provides a comprehensive overview, it does not allow for a complete description of the current transition. Instead it should provide an interesting analysis of the organizational perspective and customers' mobility behavior. The assessment of various influencing factors and related organizational activities leads to a preliminary insight into how a traditional car manufacturer copes with change. Even though results are made predictable and comprehensible, interpretations are limited to a single organization. Hence, a certain disadvantage with regard to external validity is recognized and the level of generality is limited (Eisenhardt, 1989). Langley (1999) agrees, stating that even though the method is very close to raw data and therefore high in accuracy, it is difficult to meet expectations with regard to simplicity and generalizability. However and in light of the fact that the level of generality is a point of criticism "this intimate interaction with actual evidence often produces theory which closely mirrors reality" (Eisenhardt, 1989, p. 547). Hence, in favor of internal consistency and explanatory power, this method was assessed to be particular suitable for gaining insight into strategic orientations and attitudes towards change (Langley, 1999; Miles, Huberman and Saldana, 2014; Morgan and Smircich, 1980).

\section{B. Directions for Future Research}

As stated in the introduction, the main objective of this study was to provide insights on strategic orientation and customer behavior from an organizational perspective. Since the ability to generalize outside the case is limited, there is still a need for a cross-case analysis to enhance transferability, to similar settings or other contexts. In addition to explaining the organizational viewpoints, future research should focus on the customer perspective. Quantitative and experimental approaches should be used to determine how electric and shared vehicles with autonomous driving functions are publicly accepted and which levels of differentiation, from luxury to simple solutions, are preferred. A comprehensive approach to resolve problems of increasing urbanization can be achieved with an intelligent incentive scheme and a standardized legal framework. Investigating how such a system can best encourage industry and society to make use of new opportunities in the mobility world is necessary. The fact that the currently applied management system with its dominance on standard financial figures can hinder creative and innovative ideas in an organization, but might still be best for traditional fields of activity is worth noting. It was the most unexpected observation to emerge from the data. Future research should be done in order to develop a specific steering system bringing together classical as well as creativity-enhancing measures and incentives.

\section{Acknowledgment}

We would like to thank all involved interview participants for sharing their expertise. Without their support this research would not have been possible. Our paper has benefited from feedback during different research seminars at the TUM School of Management. Laura Lang is grateful to her mentor and supervisor for their advice and guidance.

\section{References}

Bakker, S., Maat, K., \& van Wee, B. (2014). Stakeholders interests, expectations, and strategies regarding the development and implementation of electric vehicles: The case of the Netherland. Transportation Research Part A: Policy and Practice, 66, 52-64.

Bertoncello, M., \& Wee, D. (2015). Ten ways autonomous driving could redefine the automotive world. Retrieved December 15, 2017 from https://www.mckinsey.com/industries/automotive-and-assembly/ourinsights/ten-ways-autonomous-driving-could-redefine-the-automotiveworld.

Bimbraw, K. (2015, July). Autonomous cars: Past, present and future a review of the developments in the last century, the present scenario and the expected future of autonomous vehicle technology. In Proceedings of the 12th International Conference on Informatics in Control, Automation and Robotics, (pp. 191-198).

Bloom, N., Genakos, C., Sadun, R., \& Van Reenen, J. (2012). Management practices across firms and countries. Academy of Management Perspectives, 26(1), 12-33.

Bonnefon, J.-F., Shariff, A., \& Rahwan, I. (2016). The social dilemma of autonomous vehicles. Science, 352(6293), 1573-1576.

Borup, M., Brown, N., Konrad, K., \& Van Lente, Het al. (2006). The sociology of expectations in science and technology. Technology Analysis \& Strategic Management, 18(3-4), 285-298.

Brown, S.L., \& Eisenhardt, K.M. (1995). Product development: past research, present findings, and future directions. Academy of Management Review, 20(2), 343-378.

Brown, S.L., \& Eisenhardt, K.M. (1997). The art of continuous change: linking complexity theory and time-paced evolution in relentlessly shifting organizations. Administrative Science Quarterly, 42(1), 1-34.

Burns, L.D., Jordan, W.C., \& Scarborough, B.A. (2013). Transforming personal mobility. The Earth Institute - Columbia University.

Campbell, J. L., Quincy, C., Osserman, J., \& Pedersen, O. K. (2013). Coding in-depth semistructured interviews: problems of unitization and intercoder reliability and agreement. Sociological Methods \& Research, 42(3), 294-320.

Campbell, M., Egerstedt, M., How, J. P., \& Murray, R. M. (2010). Autonomous driving in urban environments: approaches, lessons and challenges. Philosophical Transactions of the Royal Society Series A, 368(1928), 4649-4672.

Canzler, W., \& Knie, A. (2016). Mobility in the age of digital modernity: why the private car is losing its significance, intermodal transport is winning and why digitalisation is the key. Applied Mobilities, 1(1), 5667.

Castellion, G., \& Markham, S.K. (2013). Perspective: new product failure rates: influence of argumentum ad populum and self - interest. Journal of Product Innovation Management, 30(5), 976-979.

Charmaz, K. (2006). Constructing grounded theory: A practical guide through qualitative analysis. London: Sage Publications.

Christensen, C.M., \& Bower, J.L. (1996). Customer power, strategic investment, and the failure of leading firms. Strategic Management Journal, 17(3), 197-218.

Council of the European Union (2017). Council Decision (EU) 2017/710 of 3 April 2017 on the position to be adopted, on behalf of the European Union, within the EEA Joint Committee concerning an amendment to Annex XX (Environment) to the EEA Agreement (CO2 Emissions).

Ederer, F., \& Manso, G. (2013). Is pay for performance detrimental to innovation? Management Science, 59(7), 1496-1513.

Eisenhardt, K.M. (1989). Building theories from case study research. Academy of Management Review, 14(4), 532-550.

Ernst, H. (2002). Success factors of new product development: a review of the empirical literature. International Journal of Management Reviews, $4(1), 1-40$.

Fagnant, D.J., \& Kockelman, K.M. (2014). The travel and environmental implications of shared autonomous vehicles, using agent-based model scenarios. Transportation Research Part C: Emerging Technologies, $40,1-13$.

Fazel, L. (2014). Akzeptanz von Elektromobilität: Entwicklung und Validierung eines Modells unter Berücksichtigung der Nutzungsform des Carsharing. Wiesbaden: Springer Gabler.

Ferreira, D., Manso, G., \& Silva, A.C. (2012). Incentives to innovate and the decision to go public or private. The Review of Financial Studies, 27(1), 256-300. 
Proc. of The Eighth Intl. Conf. On Advances In Economics, Social Science and Human Behaviour Study - ESSHBS 2018

Copyright (C) Institute of Research Engineers and Doctors, USA. All rights reserved.

ISBN: 978-1-63248-156-6 doi: 10.15224/978-1-63248-156-6-22

Garcia, R., \& Calantone, R. (2002). A critical look at technological innovation typology and innovativeness terminology: a literature review. Journal of Product Innovation Management, 19(2), 110-132.

Geels, F.W. (2005). The dynamics of transitions in socio-technical systems: a multi-level analysis of the transition pathway from horse-drawn carriages to automobiles (1860-1930). Technology Analysis \& Strategic Management, 17(4), 445-476.

Geels, F.W., \& Schot, J. (2007). Typology of sociotechnical transition pathways. Research Policy, 36(3), 399-417.

Gioia, D.A., \& Chittipeddi, K. (1991). Sensemaking and sensegiving in strategic change initiation. Strategic Management Journal, 12(6), 433448.

Glaser, B.G., \& Strauss, A.L. (1967). The discovery of grounded theory: strategies for qualitative research. Chicago: Aldine.

Gläser, J., \& Laudel, G. (2010). Experteninterviews und qualitative Inhaltsanalyse als Instrumente rekonstruierender Untersuchungen (3rd edn.). Wiesbaden: VS Verlag für Sozialwissenschaften.

Helfferich, C. (2011). Die Qualität qualitativer Daten (4th ed.). Wiesbaden: VS Verlag für Sozialwissenschaften.

Kaplan, S., \& Orlikowski, W.J. (2013). Temporal work in strategy making. Organization Science, 24(4), 965-995.

Knupfer, S., Hensley, R., Hertzke, P., Schaufuss, P., \& Laverty, N. (2017). Electrifying insights: How automakers can drive electrified vehicle sales and profitability. McKinsey\&Company.

Langley, A. (1999). Strategies for theorizing from process data. Academy of Management Review, 24(4), 691-710.

MacKay, R.B., \& Chia, R. (2013). Choice, chance, and unintended consequences in strategic change: a process understanding of the rise and fall of Northco Automotive. Academy of Management Journal, 56(1), 208-230.

Manso, G. (2011). Motivating innovation. The Journal of Finance, 66(5), 1823-1860.

Mayring, P. (2010). Qualitative Inhaltsanalyse. Grundlagen und Techniken (11th ed.). Weinheim: Beltz.

Miles, M.B., Huberman, A.M., \& Saldana, J. (2014). Qualitative data analysis: A method sourcebook (3rd ed.). Thousand Oaks CA: Sage Publications.

Morgan, G., \& Smircich, L. (1980). The case for qualitative research. Academy of Management Review, 5(4), 491-500.

O'Reilly 3rd, C.A.,, \& Tushman, M.L. (2004). The ambidextrous organization. Harvard Business Review, 82(4), 74-81.

Schilling, M.A. (1998). Technological lockout: An integrative model of the economic and strategic factors driving technology success and failure Academy of Management Review, 23(2), 267-284.

Spieser, K., Treleaven, K., Zhang, R., Frazzoli, E., Morton, D., \& Pavone, M. (2014). Toward a systematic approach to the design and evaluation of automated mobility-on-demand systems: A case study in Singapore. in Road Vehicle Automation: Springer, 229-245.

Tripsas, M., \& Gavetti, G. (2000). Capabilities, cognition, and inertia: Evidence from digital imaging. Strategic Management Journal, 21(1011), 1147-1161.

Truelove, E., \& Kellogg, K.C. (2016). The radical flank effect and crossoccupational collaboration for technology development during a power shift. Administrative Science Quarterly, 61(4), 662-701.

Wilson, K. ,\& Doz, Y.L. (2011). Agile innovation: a footprint balancing distance and immersion. California Management Review, 53(2), 6-26.
About Authors:

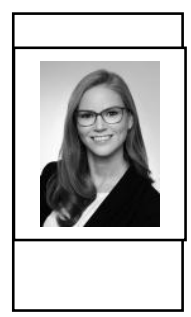

Laura Marie Lang (M.Sc.) Doctoral Candidate

at the Chair of Coporate Management at TUM School of Management,

Technische Universität München.

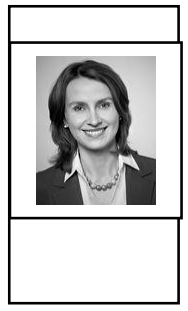

Univ.-Prof. Dr. Alwine Mohnen

Head of the Department

of Corporate Management

at TUM School of Management,

Technische Universität München. 